\title{
Preservação da proteína verde fluorescente no tecido ósseo descalcificado
}

\author{
Preservation of the green fluorescent protein on decalcified bone tissue
}

\author{
Jankerle Neves Boeloni' ${ }^{\mathrm{I}}$ Natália de Melo Ocarino ${ }^{\mathrm{I}}$ Rafaela Chitarra Rodrigues Hell $^{\mathrm{I}}$ \\ Guilherme Resende da Silva ${ }^{\mathrm{I}}$ Alfredo Miranda Goes ${ }^{\mathrm{II}}$ Dawidson Assis Gomes ${ }^{\mathrm{II}}$ Rogéria Serakides $^{\mathrm{F}}$
}

RESUMO

A proteína verde fluorescente (GFP) foi originalmente descoberta no cnidário Aequorea victoria. Células-tronco GFP positivas podem ser rastreadas in vivo quando usadas na terapia de doenças. No entanto, no osso, a fluorescência gerada pela GFP pode ser perdida durante o processo de descalcificação, dificultando o rastreamento das células-tronco usadas no tratamento de doenças ou defeitos ósseos. O objetivo deste estudo foi comparar diferentes técnicas de preservação da GFP no tecido ósseo descalcificado. Foram utilizados fêmures de ratas GFP Lewis distribuídos em quatro grupos: 1) descalcificado em ácido fórmico e incluído em parafina; 2) descalcificado em ácido fórmico e submetido à criomicrotomia; 3) descalcificado em EDTA e incluído em parafina; e 4) descalcificado em EDTA com criomicrotomia. Secções de tecido ósseo de todos os grupos foram analisadas para identificação da fluorescência natural e posteriormente submetidas à imunofluorescência, sendo utilizados anti-GFP e Alexa Flúor 555. As imagens foram obtidas por microscopia confocal. Osteócitos, osteoblastos e células da medula óssea de ratos GFP somente tiveram sua fluorescência natural preservada no tecido ósseo descalcificado em EDTA e submetido à microtomia por congelação. Nos demais grupos, houve perda da fluorescência natural, e as células GFP somente puderam ser identificadas com o uso da reação de imunofluorescência com anti-GFP. Conclui-se que a descalcificação em EDTA e a criomicrotomia são as melhores técnicas para preservar a fluorescência natural das células GFP no tecido ósseo e que a visualização de células GFP em tecido ósseo descalcificado em ácido fórmico e incluído em parafina somente pode ser realizada com o uso da técnica de imunofluorescência.

Palavras-chave: proteína verde fluorescente (GFP), descalcificação, osso.

\begin{abstract}
Green fluorescent protein (GFP) was originally derived from the cnidarians Aequorea victoria. GFPpositive stem cells can be tracked in vivo when used in the therapy of diseases. However, in the bone, the fluorescence generated by GFP can be lost during the decalcification process, hindering the tracking of stem cells used in the treatment of diseases or bone defects. The aim of this study was to compare different techniques of preservation of GFP in the decalcified bone tissue. Femurs of female Lewis GFP rats were distributed in four groups: 1) decalcified in formic acid and paraffin-embedded;2) decalcified in formic acid submitted to cryomicrotomy; 3) decalcified in EDTA and paraffin-embedded and 4) decalcified in EDTA with cryomicrotomy. Sections of bone tissue of all the groups were analyzed for identification of the natural fluorescence and subsequently submitted to the immunofluorescence using anti-GFP and Alexa Flúor 555. The images were obtained by confocal microscopy. Osteocytes, osteoblasts and bone marrow cells of GFP rats only had natural fluorescence preserved in the bone tissue decalcified in EDTA and submitted to cryomicrotomy. In others groups there were loss of the natural fluorescence and the GFP cells could be only identified with the use of the immunofluorescence with anti-GFP. In conclusion, the decalcification in EDTA and the cryomicrotomy are the best techniques to preserve the natural fluorescence of the GFP cells in the bone tissue and the GFP cells in bone tissue decalcified in formic acid and paraffin-embedded can be visualized only with the use of the immunofluorescence with anti-GFP.
\end{abstract}

Key words: green fluorescent protein (GFP), decalcification, bone.

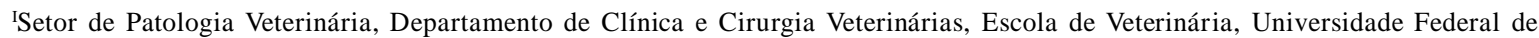
Minas Gerais (UFMG). Av. Pres. Antônio Carlos, 6.627, CP 567, 31270-901, Belo Horizonte, MG, Brasil. E-mail: serakidesufmg@gmail.com.*Autor para correspondência.

IIDepartamento de Bioquímica e Imunologia, Instituto de Ciências Biológicas, UFMG, Belo Horizonte, MG, Brasil. 


\section{INTRODUÇÃO}

A proteína verde fluorescente (GFP) é uma proteína originalmente descoberta no cnidárioAequorea victoria, sendo responsável pela bioluminescência verde desse cnidário, necessitando somente de excitação da luz para a sua autofluorescência (TSIEN, 1998). Desde a sua descoberta, a GFP vem sendo utilizada para estudar vários fenômenos biológicos (TADA et al., 2006). Atualmente, ela é considerada o marcador celular ideal utilizado na terapia celular no que se refere ao rastreamento das células in vivo, pois sua expressão não é perdida durante o processo de replicação e diferenciação celulares, diferentemente do que é observado com outros marcadores, como o 4',6diamidino-2-fenilindole (DAPI) (OCARINO et al., 2008; CASTANHEIRA et al., 2009), a bromodeoxiuridina (MCDONALD et al., 1999) e oCM-Dil(WEIR et al., 2008).

Células GFP positivas podem ser extraídas de espécies animais geneticamente modificadas, em que o gene responsável pela expressão da GFP é inserido no genoma do animal, fazendo com que todas as células desse indivíduo, inclusive as células-tronco, expressem fluorescência quando visualizadas sob luz fluorescente (OKABE et al., 1997; TAGUCHI et al., 2005; TADA et al., 2006).

Estudos utilizando células-tronco na terapia celular de diversas doenças, incluindo as doenças ósseas, vem sendo cada vez mais realizados pela comunidade científica (ARINZEH, 2005; GRANEROMOLTO et al., 2008; UNDALE et al., 2009). O uso de células-tronco GFP no tratamento das doenças ósseas pode ser importante para verificar se os efeitos positivos observados (OSHIMA et al., 2005) se devem ao fato de as células tronco utilizadas sintetizarem matriz óssea in vivo ou se devem ao fato destas estimularem os osteoblastos pré-existentes a produzirem osteoide.

O tecido ósseo se constitui de uma matriz orgânica mineralizada, sendo necessário o uso de secções ósseas descalcificadas com produtos químicos, como ácido fórmico e EDTA. Entretanto, o uso das soluções descalcificadoras prejudica a visualização das células GFP por provocar a perda da fluorescência natural dessas células (HARMS et al., 2002; TADA et al., 2006). Outro fator que promove a perda da fluorescênica natural das células GFP é a utilização da técnica rotineira de inclusão em parafina (JIANG et al., 2005), fazendo-se necessária a reação de imunofluorescência com anticorpo anti-GFP. Entretanto, esse anticorpo não possui $100 \%$ de especificidade, o que subestima a visualização do número de células GFP positivas que foram utilizadas no processo de terapia celular. Assim, a descoberta de técnicas alternativas aplicadas ao tecido ósseo descalcificado que impeçam a perda da fluorescência natural gerada pela GFP é pertinente e possibilitará avanços nos estudos que utilizam células GFP no tratamento das doenças ósseas.

Não há estudos que tenham comparado diferentes técnicas histológicas aplicadas ao tecido ósseo descalcificado para preservação da GFP e que tenham comparado a preservação da fluorescência natural das células GFP com os resultados gerados a partir da reação de imunofluorescência com anticorpo anti-GFP, sendo estes os objetivos deste estudo.

\section{MATERIAL E MÉTODOS}

Foram utilizados fêmures de ratas GFP Lewis com um mês de idade distribuídos em quatro grupos: 1) descalcificado em ácido fórmico e incluído em parafina; 2) descalcificado em ácido fórmico e submetido à criomicrotomia; 3) descalcificado em EDTA e incluído em parafina; e 4) descalcificado em EDTA e submetido à criomicrotomia.

Os fêmures dos grupos 1 e 3 foram fixados em formalina neutra e tamponada, com fosfato a $10 \%$ e posteriormente dissecados. Os ossos foram descalcificados em solução de ácido fórmico a $10 \%$ (Grupo 1) ou em EDTA (Grupo 3), por 30 dias, e processados, em seguida, pela técnica rotineira de inclusão em parafina. Secções histológicas de $5 \mu \mathrm{m}$ foram obtidas para posterior avaliação pela microscopia confocal.

Os fêmures dos grupos 2 e 4 foram fixados em formalina neutra e tamponada, com fosfato a $10 \%$, dissecados e posteriormente descalcificados em solução de ácido fórmico a 10\% (Grupo 2) ou em EDTA (Grupo 4), por 30 dias. Em seguida, foram colocados em uma solução de sacarose a $20 \%$, a $4^{\circ} \mathrm{C}$, por 24 horas. Posteriormente, foram congelados em criostato (Leica CM1510S, Leica Mycrosystems, Wetzlar, Germany), incluídos em gel (Tissue Freezing Medium, Leica Instruments, Nussloch, Germany) e armazenados a $-80^{\circ} \mathrm{C}$. Secções histológicas de $14 \mu \mathrm{m}$ foram obtidas em criostato para posterior avaliação pela microscopia confocal.

Secções de tecido ósseo de todos os grupos foram analisadas sem a reação de imunofluorescência para verificar a preservação da fluorescência natural da GFP. Secções de tecido ósseo de todos os grupos também foram submetidas à reação de imunofluorescência utilizando anticorpo primárioanti-GFP(1:500) e anticorpo secundárioAlexa Flúor 555 (1:200). Inicialmente, os cortes foram desparafinizados em xilol (somente dos grupos 1 e 3) e em seguida hidratados em concentrações decrescentes de álcool etílico (100\%, 90\% e $80 \%)$. As secções histológicas foram então lavadas em água 
destilada, incubadas com peróxido de hidrogênio (10V) e posteriormente colocadas em uma mistura de peróxido de hidrogênio (30V) e metanol em temperatura ambiente. As secções foram lavadas em PBS (solução tampão de fosfato padrão) e colocadas em solução de bloqueio (Mistura de PBS, Triton X-100a 0,25\% [Roche, Germany] e BSA a 2\% [Albumin, Bovine, Sigma-Aldrich, St. Louis, MO, USA]) por 60 minutos, em temperatura ambiente. Posteriormente, as secções foram lavadas em PBS e incubadas com anticorpo primário anti-GFP (Abcam, Cambridge, UK) overnight a $4^{\circ} \mathrm{C}$, com diluição de 1:500. Depois de lavadas em PBS, as secções foram incubadas com anticorpo secundário Alexa Flúor 555 (Molecular Probes), na diluição de 1:200, por 30 minutos, em temperatura ambiente. Posteriormente, as lâminas foram montadas com lamínulas com o uso de Hydramount (National Diagnostics, Somerville, NJ). As imagens das células GFP, submetidas ou não à reação de imunofluorescência, foram obtidas por microscopia confocal (Olympus ${ }^{\circledR}$, Germany), com excitação a 488nm e observação a 500-525nm, para detectar GFP, e excitação a 543nm e observação a 560-675nm, para detectar Alexa Flúor 555.

\section{RESULTADOS E DISCUSSÃO}

Em todos os grupos estudados, as secções histológicas dos fêmures (Figuras 1A, 1D, 1G e 1J) foram

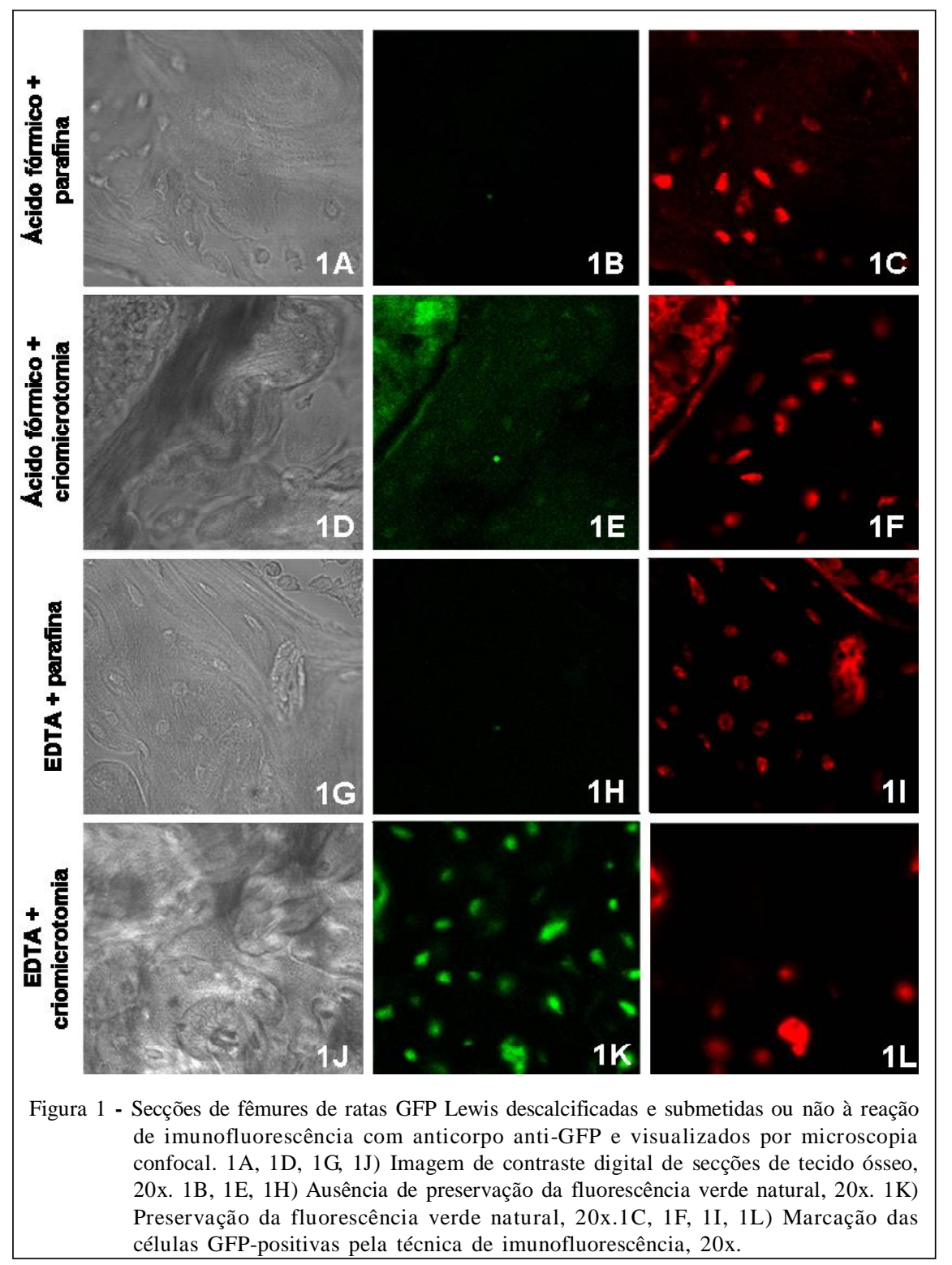

Ciência Rural, v.40, n.10, out, 2010. 
analisadas sem a reação de imunofluorescência com anticorpo anti-GFP e observou-se a preservação da fluorescência natural somente no grupo 4, ou seja, a fluorescência natural foi preservada somente no tecido ósseo descalcificado em EDTAe submetido à microtomia por congelação, e todas as células, como osteócitos, osteoblastos e células da medula óssea de ratos GFP, tiveram sua fluorescência natural preservada (Figura 1K). Nos demais grupos, houve perda da fluorescência natural (Figuras 1B, 1E e 1H), e as células GFP-positivas somente puderam ser identificadas com o uso da reação de imunofluorescência com anti-GFP (Figuras 1C, 1F e 1I). Assim, o grupo 4 foi o único grupo em que a fluorescência natural foi preservada (Figura 1K), e a reação de imunofluorescência somente confirmou a presença de células GFP-positivas. No entanto, nesse grupo, as células GFP foram mais bem visualizadas em secções sem o uso da reação de imunofluorescência, em comparação com as secções submetidas à reação de imunofluorescência com anti-GFP (Figura 1L), o que permite reafirmar que o anticorpo anti-GFP não apresenta $100 \%$ de especificidade e que é preciso dar preferência à realização de técnicas histológicas que preservam a fluorescência natural da GFP. Além disso, a exclusão da técnica de imunofluorescência minimiza o custo e aumenta a rapidez na obtenção dos resultados.

\section{CONCLUSÃO}

Conclui-se que a descalcificação em EDTAe a criomicrotomia são as melhores técnicas para preservar a fluorescência natural das células GFP no tecido ósseo e que a visualização de células GFP, em tecido ósseo descalcificado em ácido fórmico e incluído em parafina, somente pode ser realizada com o uso da técnica de imunofluorescência.

\section{AGRADECIMENTOS}

Os autores agradecem pelo apoio financeiro fornecido pelo Conselho Nacional de Desenvolvimento Científico e Tecnológico (CNPq) e pela Fundação de Amparo à Pesquisa do Estado de Minas Gerais (FAPEMIG).

\section{COMITÊ DE ÉTICA E BIOSSEGURANÇA}

Este estudo foi realizado sob aprovação do Comitê de Ética em Experimentação Animal da UFMG, sob protocolo 134/2008, tendo sido respeitados todos os preceitos éticos de proteção aos animais.

\section{REFERÊNCIAS}

ARINZEH, T.L. Mesenchymal stem cells for bone repair: preclinical studies and potential orthopedic applications. Foot and Ankle Clinics, v.10, n.4, p.651-665, 2005. Disponível e m : < h t t p : // w w w s c i e n c ed i r e t. c o m / science?_ob=ArticleURL\&_udi=B75J5-4HK6YS5-9\&_user= $686413 \&$ \&coverDate $=12 \% 2 \mathrm{~F} 31 \% 2 \mathrm{~F} 2005 \& \_\mathrm{rdoc}=1 \&$ \&fmt $=$ high $\&$ _ orig $=$ search \&_sort $=d \& \_$docanchor $=\& v i e w=c \& \_a c c t=C 000037$ $539 \&$ \&ersion $=1 \&$ \&_urlVersion $=0 \&$ \& u serid $=686413 \&$ md5=388c1099141fd418ecc1e70c09649e14>. Acesso em: 03 nov. 2009. doi: 10.1016/j.fcl. 2005.06.004.

CASTANHEIRA, P. et al. DAPI diffusion after intravitreal injection of mesenchymal stem cells in the injured retina of rats. Cell Transplantation, v.18, n.4, p.423-431, 2009. Disponível em: <http://www.ingentaconnect.com/content/cog/ ct/2009/00000018/00000004/ art00004>. Acesso em: 25 ago. 2009. doi: $10.3727 / 096368909788809811$.

GRANERO-MOLTO, F. et al. Role of mesenchymal stem cells in regenerative medicine: application to bone and cartilage repair. Expert Opinion on Biological Therapy, v.8, n.3, p.255-268, 2008. Disponível em: <http://informahealthcare.com/doi/pdf/ 10. 1517/14712598. 8.3.255>. Acesso em: 12 nov. 2009. doi: 10.1517/14712598.8.3.255.

HARMS, J.F. et al. Maintaining GFP tissue fluorescence through bone decalcification and long-term storage. BioTechniques, v.33, n.6, p.1197-1200, 2002. Disponível em: <http:// www.biotechniques.com/search.do?pageNumber $=1 \&$ sectionName $=\mathrm{H}$ ome $\&$ key $=$ Maintaining $\% 20$ GFP $\% 20$ tissue $\% 20$ fluores cence $\% 20$ through $\% 20$ bone $\% 20$ decalcification\%20and\%20longterm\%20storage>. Acesso em: 15 nov, 2009. doi: 12120023.

JIANG, X. et al. Histological analysis of GFP expression in murine bone. Journal of Histochemistry and Cytochemistry, v.53, n.5, p.593-602, 2005. Disponível em: <http://www.jhc.org/cgi/reprint/53/5/593>. Acesso em: 07 jul. 2009. doi: 10.1369/jhc.4A6 401.2005.

MCDONALD, J.W. et al. Transplanted embryonic stem cells survive, differentiate and promote recovery in injured rat spinal cord. Nature Medicine, v.5, p.1410-1402, 1999. Disponível em: <http://www.nature.com/nm/journal/v5/n12/pdf/ nm1299_1410.pdf>. Acesso em: 04 jul. 2008. doi: 10.1038/ 70986.

OCARINO, N.M. et al. Behavior of mesenchymal stem cells stained with 4', 6-diamidino-2-phenylindole dihydrochloride (DAPI) in osteogenic and non osteogenic cultures. Biocell, v.32, n.2, p.175-183, 2008. Disponível em: <http:// www.scielo.org.ar/pdf/biocell/v32n2/v32 n2a03.pdf.>. Acesso em: 12 abr. 2009.

OKABE, M. et al. 'Green mice" as a source of ubiquitous green cells. FEBS Letters, v.407, p.313-319, 1997. Disponível em: $<$ http://www.sciencedirect.com/science?_ob=MImg\&_ $\mathrm{i} \mathrm{m} \mathrm{a} \mathrm{g} \mathrm{e} \mathrm{k} \mathrm{e} \mathrm{y}=$ B 6 T $36-3 \mathrm{R} 85 \mathrm{~J} \mathrm{M} \mathrm{S}-\mathrm{B} 1$ F\&_cdi $=4938 \&$ _user $=686413 \&$ \& \&_orig = s e a r ch \&_cover Date $=05 \% 2 \mathrm{~F} 05 \%$ 2 F $1997 \&$ \& sk $=995929996 \&$ view $=c \& w c h p=d G L z V 1 b-$ zSkzS\&md5=b5f27c6e20a16d1842e255688d8af93a\&ie=/ sdarticle.pdf $>$. Acesso em: 23 abr. 2009. doi: 10.1016/S00145793(97)00313-X.

OSHIMA, Y. et al. Behavior of transplanted bone marrowderived GFP mesenchymal cells in osteochondral defect as a simulation of autologous transplantation. Journal of Histochemistry and Cytochemistry, v.53, n.2, p.207-216, 2005. Disponível em: <http://www.jhc.org/cgi/content/full/53/ 
2/207>. Acesso em: 23 nov. 2008. doi: 10.1369/jhc.4A 6280.2005 .

TADA, M. et al. Preparation and observation of fresh-frozen sections of the green fluorescent protein transgenic mouse head. Acta Histochemica et Cytochemica, v.39, n.2, p.31-34, 2006. Disponível em: < http://www.ncbi.nlm.nih.gov/pmc/ articles/PMC1828081/?tool= pubmed $>$. Acesso em: 05 jul. 2009. doi: $10.1267 /$ ahc.05051.

TAGUCHI, K. et al. The role of bone marrow-derived cells in bone fracture repair in a green fluorescent protein chimeric mouse model. Biochemical and Biophysical Research Communications, v.331, p.31-36, 2005. Disponível em: < h t t p : / / w w w. s c i e n c e di r e c t. c o m / science?_ob=ArticleURL\&_udi=B6WBK-4FT0N9W$7 \&$ u s e r $=686413 \&$ \& o v e r D a t e $=0$ $5 \% 2 \mathrm{~F} 27 \% 2 \mathrm{~F} 2005 \& \_\mathrm{rdoc}=1 \&_{-} \mathrm{fmt}=\mathrm{high} \&$ _orig $=$ sea $\mathrm{rch} \&$ _sort $=\mathrm{d} \&$ _docanchor $=\&$ vie w $=\mathrm{c} \&$ _acct $=\mathrm{C} 0$ $00037539 \&$ \& version $=1 \&_{\text {_ur }} 1$ Version $=0 \&$ \& user $\mathrm{id}=686413 \& \mathrm{md} 5=2022 \mathrm{ca} 4189 \mathrm{~b} 02496 \mathrm{c} 5 \mathrm{a} 99 \mathrm{a} 33512607 \mathrm{f} 0>$. Acesso em: 12 ago. 2009. doi: 10.1016/j.bbrc.2005.03.119.
TSIEN, R.Y. The green fluorescent protein. Biochemical and Biophysical Research Communications, v.67, p.509544, 1998. Disponível em: <http://arjournals.annual reviews.org/ doi/abs/10.1146/annurev.biochem.67.1.509>. Acesso em: 26 set. 2008. doi: 10.1146/annurev.biochem.67.1.509.

UNDALE, A.H. et al. Mesenchymal stem cells for bone repair and metabolic bone diseases. Mayo Clinic Proceedings, v.84, n.10, p.893-902, 2009. Disponível em: < http://www. mayoclinicproceedings.com/content/84/10/893.long>. Acesso em: 30 nov. 2008. doi: 10.40 65/?84.10.893.

WEIR, C. et al. Mesenchymal stem cells: isolation, characterization and in vivo fluorescent dye tracking. Heart, Lung \& Circulation, v.17, n.5, p.395-403, 2008. Disponível em: <http:// www.sciencedirect.com/science?_ob=ArticleURL\&_udi=B7CW24S7HSHJ-2\&_user $=687358 \&$ \& coverDate $=10 \% 2 \mathrm{~F} 31 \% 2 \mathrm{~F} 20$ $08 \& \_r d o c=1 \&$ fmt $=$ high \&_orig $=$ search\&_origin $=$ search $\&$ _sort $=\mathrm{d} \&$ _docanchor $=\&$ view $=\mathrm{c} \&$ \&searchStrId $=1478555$ 031\&_rerunOrigin=google\&_acct $=$ C000037899\&_version $=1$ \&_urlV e rs i on $=0 \&$ u s e ri d $=687358 \&$ m d $5=5$ e 2 $5 \mathrm{~b} 2 \mathrm{e} 3 \mathrm{~d} 6 \mathrm{fc} 2 \mathrm{~b} 14 \mathrm{fa} 961 \mathrm{e} 460186 \mathrm{c} 3 \mathrm{f} 0 \&$ searchtype $=\mathrm{a}>$. Acesso em: 24 out. 2008. doi: 10.1016/j.hlc.2008.01.006. 